\title{
STUDY OF AIR QUALITY AT ONE OF THE WORLD'S MOST DENSELY POPULATED CITY DHAKA AND ITS SUBURBAN AREAS
}

\author{
MOHAMMAD LOKMAN HOSSAIN ${ }^{1 *}$, SUBRATA CHANDRA ROY ${ }^{1}$, MITHUN CHANDRA \\ BEPARI $^{1}$, AND BILKIS ARA BEGUM ${ }^{2}$ \\ ${ }^{1}$ Department of Chemistry, Jagannath University, Dhaka-1100, Bangladesh
}

\begin{abstract}
Air borne particulate matter $\mathrm{PM}_{10}$ and $\mathrm{PM}_{2.5}$ were collected by using Mini Vol portable Air Sampler from the world most densely populated city Dhaka and its suburban areas over a period of January through December in 2016. This study revealed a comparison of atmospheric particulate matter (PM) of a highly polluted urban area to its two neighboring areas that accommodate heavy oil based power plants. In all three sites the quantity of PM decreases in summer reaching its lowest level in the month of July, however, it increases significantly in winter season. Despite the presence of the fuel based power plants the average concentrations of $\mathrm{PM}_{10}$ and $\mathrm{PM}_{2.5}$ at the city Dhaka surpasses its two neighbors Manikganj and Nawabganj. Interestingly, $\mathrm{PM}_{2.5} / \mathrm{PM}_{10}$ ratio is higher at the suburban areas than urban area. The study shows that for all the sites $\mathrm{PM}_{2.5}$ is approximately twice than that of WHO and USEPA. However, the values of $\mathrm{PM}_{2.5}$ is almost similar for Nawabganj and Manikganj but much higher for the Dhaka city especially during dry season. The Mass concentration of Black Carbon (BC) was also determined from the PM samples from Manikganj and Nawabganj.
\end{abstract}

Keywords: Particulate Matter, $\mathrm{PM}_{2.5} / \mathrm{PM}_{10}$ Ratio, $\mathrm{BC}$

\section{INTRODUCTION}

According to Clean Air and Sustainable Environment [CASE, DoE] on $23^{\text {rd }}$ November 2015, Air Quality Index (AQI) value of Dhaka city was "211", which was designated as "very unhealthy" for human health. The AQI tells how clean or polluted the air is. AQI was developed by the United States Environmental Protection Agency (EPA) in 1968. It ranks in the range of $0-500$. The AQI score below 50 is classified as "good" quality of air at that area. The higher the value of AQI, the worse air quality is. AQI is based on the presence of five types of air pollutant present in air e.g. particulate matter $\left(\mathrm{PM}_{10}\right.$ and $\left.\mathrm{PM}_{2.5}\right)$, ground level ozone $\left(\mathrm{O}_{3}\right)$, nitric oxide (NO), sulphur dioxide $\left(\mathrm{SO}_{2}\right)$, and carbon monooxide $(\mathrm{CO})$.
Dhaka is one of the densely populated megacities in the world (density 42,596/ $\mathrm{Km}^{2}$ ) [BANBEIS]. According to Bangladesh Road Transport Authority (BRTA) from 2010 up to April 2018, the number of registered motor vehicles in the Dhaka city is $11,15,654$. This causes severe traffic jam due to very limited metaled road $(1594 \mathrm{~km})$ [BANBEIS]. Therefore, larger number of motor vehicles exhaust containing PM is emitted and causes serious air pollution. Similarly, exhaust from brick kilns, unplanned industries, construction work, and long-range transport cause the air pollution [Azad and Kitada 1998, Salam et al. 2011]. Particulate matters, $\mathrm{PM}_{10}$ and $\mathrm{PM}_{2.5}$, both have severe impact on morbidity and premature mortality [Kojima

*Corresponding author: <lokmanchemju@yahoo>.

${ }^{2}$ Atomic Energy Center, Dhaka, Bangladesh Atomic Energy Commission, Dhaka-1000 Bangladesh 
et al. 2000, Lin and Lee 2004, Namdeo and Bell 2005]. Specially, $\mathrm{PM}_{2.5}$ is a serious health hazard. It directly enters into the lung alveoli and aggravates diseases in the respiratory system. The PM also absorbs and scatters solar radiation that changes the proportion of solar albedo, and thus exerts tremendous effect on atmospheric photochemical reactions as well as on global warming. Furthermore, PM severely affects the visibility that often creates harmful incidents.

In $31^{\text {st }}$ December 2002, Bangladesh Government banned two-stroke three wheeler vehicles which significantly improved the air quality in Dhaka city because of the reduction of mass concentration of both PM and black carbon (BC) [Begum et al. 2006]. In addition to this great effort, further reduction of the PM concentration to the targeted and satisfactory level, detailed knowledge of their sources is essential to understand. This motivated for a study on concentration of air borne $\mathrm{PM}_{10}$ and $\mathrm{PM}_{2.5}$ and $\mathrm{BC}$ at three different sites: Dhaka city, Nawabganj and Manikganj and to compare the data to standard values recommended by WHO, USEPA, and BNAAQS. The $\mathrm{PM}_{2.5} / \mathrm{PM}_{10}$ ratio of the most densely populated city Dhaka is also compared with its suburban areas Nawabganj and Manikganj where heavy fuel oil based power plants were established in 2012 and since then each of these are producing $55 \mathrm{MW}$ electricity. Here, this study presents a broad spectrum as to how the atmosphere of the city Dhaka compares to its neighborhoods where the atmosphere is contaminated both by the heavy traffic as well as fuel based powerplants.

\section{MATERIALS AND METHODS}

\section{Site description}

(a) Sampling site at Dhaka city: This sampling location was at the Bangladesh Atomic Energy Center, Dhaka-1000, Bangladesh as shown in Fig. 1. Site (a), latitude $23^{\circ} 43{ }^{\prime} 51.4^{\prime \prime N}$, longitude $90^{\circ} 23^{\prime}-47.5^{\prime \prime} \mathrm{E}$. This site is positioned inside the Dhaka University campus which is at the center of greater Dhaka. Therefore, the traffic volume is considered too high in this area.

(b) Sampling site at Manikganj: This sampling location was inside a power plant (Dhaka Northern Power Generations Ltd.) which is situated at Dhalla Union as shown Fig. 1 site (b), latitude $23^{\circ} 48^{\prime} 32.1 " \mathrm{~N}$, longitude $90^{\circ} 1434.7 \mathrm{E}$, under Manikganj District and adjacent to the Dhaka district. There are agricultural lands around this site.

(c) Sampling site at Nawabganj: This sampling location was also inside a power plant (Dhaka Southern Power Generations Ltd.) which is situated at Daulatpur, Nawabganj upzilla under Dhaka district as shown in Fig. 1 site (c), latitude $\quad 23^{\circ} 40^{\prime}-\quad 12.60 " \mathrm{~N}, \quad$ longitude $90^{\circ} 16$ '57.50"E. There is a school as well as a graveyard to the north-west \& north-east side of the plant respectively. There are agricultural lands on the west side and south side of the plant area. There are some scattered settlements at the north-east, east and south east of the plant area near the road side. The location is well connected by both road and river-ways with surroundings areas.

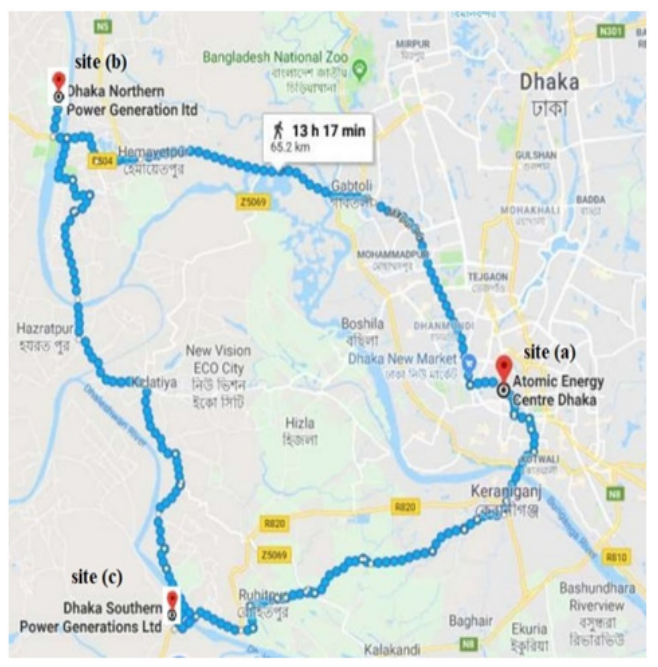

Fig. 1. Satellite view of three different sites Dhaka city (a), Manikganj (b), and Nawabganj (c). 


\section{Sampling of particulate matter (PM)}

The sampling of air particulate matter was performed on monthly basis from January through December 2016 by using MiniVol portable Air Sampler (Air Metrics, USA) for collecting $\mathrm{PM}_{2.5}$ and $\mathrm{PM}_{10}$, on Teflon filter paper and glass filter paper, respectively at three different study sites: Nawabganj, Manikganj and Dhaka city. Samples were collected only on working days for every 24 hours. The samplers were placed on a table which is about 4.5 feet in height from the ground. The Particulate Matter $\left(\mathrm{PM}_{2.5}\right.$ and $\left.\mathrm{PM}_{10}\right)$ and $\mathrm{BC}$ were determined from both types of filter papers. The effect of meteorological parameter (e.g., wind direction, wind speed, humidity and temperature) on the air pollution was also studied.

Analysis of PM and Black Carbon (BC)

A microbalance (METTLER Model MT5) was used to determine the masses of PM $\left(\mathrm{PM}_{2.5}\right.$ and $\mathrm{PM}_{10}$ ) gravimetrically by weighing the filter before and after exposure [Begum et al. 2006]. Before each weighing the static charge accumulated on the filters was eliminated by A Po-210 (alpha emitter) electrostatic charge eliminator (STATICMASTER). The air filters were equilibrated at constant temperature of the balance room for 48 hours before every weighing. The temperature and humidity of the balance room were $22{ }^{\circ} \mathrm{C}$ and $50 \%$, respectively. The laboratory blank filters were used for humidity correction. The Mass Concentration (MC) of PM were calculated from Eq. 1 and Eq. 2.

$\operatorname{MC}\left(\mathrm{PM}_{2.5}\right)=\Delta \mathrm{W} / \mathrm{V}\left(\mu \mathrm{g} / \mathrm{m}^{3}\right)$

$\mathrm{MC}\left(\mathrm{PM}_{10}\right)=\left(\mathrm{NWPM}_{25}+\mathrm{NWPM}_{25-10}\right) / \mathrm{V}\left(\mu \mathrm{g} / \mathrm{m}^{3}\right)$ Eq. 2

Where, $\Delta \mathrm{W}=$ Mass of sample $(\mu \mathrm{g}) ; \mathrm{V}=$ Mass of air volume $\left(\mathrm{m}^{3}\right) ; \mathrm{NW}=$ Net weight of $\mathrm{PM}_{2.5}$, $\mathrm{PM}_{10} ;$ and $\mathrm{v}=\frac{\frac{\left(Q_{\text {Ini }}+Q_{\text {fin }}\right) \times t \times 60}{2}}{1000}$

$\mathrm{Q}_{\text {Ini, }}, \mathrm{Q}_{\text {Fin }}=$ Initial and final flow rate at starting and end time of sampling; $\mathrm{t}=$ Sampling time (hrs.);
An EEL type Smoke Stain Reflectometer M43D (Diffusion system Ltd.) [Biswas et al. 2003] was used to calculate BC content from the aerosols deposited on the filters during the sampling period by reflectance measurement. The reflectometer was calibrated using secondary standard of known concentration of black carbon. The masses concentration of PM and BC content were measured in the laboratory of Chemistry Division, Atomic Energy Center Dhaka (AECD).

\section{Meteorological Condition}

In Bangladesh, the climate is characterized by high temperature and high humidity during most of the year and also distinctly marked seasonal variation of precipitation. According to meteorological condition, the year can be divided into three seasons, short and hot spring (March-May), long rainy season (JuneNovember) due to monsoon, sunny and warm winter (December-February). January is the coolest and April is the warmest month with temperature averaging $26^{\circ} \mathrm{C}$ and $36^{\circ} \mathrm{C}$, respectively. It rains mostly during June to October. From November to February, the general directions of the winds are north-easterly in the northern region. From March to May, the winds are westerly or south-westerly in the western half. From June to September, the winds are not all southerly; much of it is either southeasterly or easterly [Banglapedia].

\section{RESULTS AND DISCUSSION}

\section{PM Mass Concentration}

Monthly variation of $\mathrm{PM}_{10}, \mathrm{PM}_{2.5}$ and black carbon concentration from January to December, 2016 at three different sites Dhaka, Nawabganj, and Manikganj in Bangladesh along with their meterological conditions is shown in Fig. 2. Both the particulate matters, $\mathrm{PM}_{10}$ and $\mathrm{PM}_{2.5}$, in all three sites have lowest concentration in the month of July when the seasonal rain is plenty, and highest in concentration in the months of January and December (winter season, Table 1). The lowest value of PM mass 
concentration in July is mainly due to hot and humid meteorological condition during this month. Neither the high temperature nor the humidity is singly responsible to reduce the PM mass concentration. Therefore, relatively hot humid weather is required to coagulate the PM respectively. On the other hand, the minimum concentration of $\mathrm{PM}_{10}$ is 39.2 , 48.0, and 33.1 $\mu \mathrm{g} / \mathrm{m}^{3}$ whereas the highest value is 203.0, 152.0, and $285.0 \mu \mathrm{g} / \mathrm{m}^{3}$ at Nawabganj, Manikganj, and Dhaka city, respectively.

Table 1. The values of $\mathrm{PM}_{10}, \mathbf{P M}_{2.5}$ and $\mathrm{BC}$ concentrations $\left(\mu \mathrm{g} / \mathrm{m}^{3}\right)$ in all three sites during the sampling periods (unit: $\left(\mu \mathrm{g} / \mathrm{m}^{3}\right)$

\begin{tabular}{|c|c|c|c|c|c|c|c|c|}
\hline \multirow{2}{*}{ Date } & \multicolumn{2}{|l|}{ Dhaka } & \multicolumn{3}{|c|}{ Manikganj } & \multicolumn{3}{|c|}{ Nawabganj } \\
\hline & $\mathbf{P M}_{10}$ & $\mathbf{P M}_{2.5}$ & $\mathbf{P M}_{10}$ & $\mathbf{P M}_{2.5}$ & BC & $\mathbf{P M}_{10}$ & $\mathbf{P M}_{2.5}$ & BC \\
\hline $01 / 23 / 16$ & 241.0 & 162.5 & 231 & 181 & 16.3 & 203.0 & 152.0 & 15.3 \\
\hline $02 / 19 / 16$ & 283.0 & 140.5 & 165 & 96.1 & 11.7 & 155.0 & 86.0 & 11.2 \\
\hline $03 / 18 / 16$ & 242.0 & 97.4 & 143 & 93.9 & 10.9 & 122.0 & 83.0 & 14.0 \\
\hline $04 / 11 / 16$ & 111.0 & 45.1 & 105 & 71.6 & 6.4 & 75.6 & 52.2 & 5.4 \\
\hline $05 / 13 / 16$ & 92.3 & 53.9 & 66.3 & 47.9 & 4.3 & 56.3 & 40.0 & 8.4 \\
\hline $06 / 03 / 16$ & 60.9 & 28.2 & 52.8 & 41.8 & 3.7 & 82.8 & 58.8 & 3.6 \\
\hline 07/09/16 & 33.1 & 18.3 & 48.0 & 31.7 & 2.8 & 39.2 & 25.8 & 3.0 \\
\hline $08 / 25 / 16$ & 72.7 & 28.8 & 51.3 & 45.3 & 4.1 & 49.3 & 39.1 & 11.1 \\
\hline $09 / 17 / 16$ & 72.5 & 27.7 & 52.3 & 39.2 & 3.5 & 41.3 & 31.9 & 5.2 \\
\hline $10 / 11 / 16$ & 85.4 & 52.5 & 62.7 & 47.0 & 4.2 & 56.4 & 31.9 & 3.6 \\
\hline $11 / 17 / 16$ & 139.0 & 108.6 & 66.1 & 46.4 & 4.2 & 70.1 & 45.6 & 6.3 \\
\hline $12 / 08 / 16$ & 285.0 & 178.6 & 141.0 & 98.5 & 15.8 & 153 & 101 & 27.1 \\
\hline $\begin{array}{l}\text { Average } \\
\pm \mathrm{SD}\end{array}$ & $\begin{array}{l}143.16 \pm 9 \\
2.85\end{array}$ & $\begin{array}{l}78.52 \\
\pm 57.05\end{array}$ & $\begin{array}{l}98.71 \\
\pm 58.91\end{array}$ & $\begin{array}{l}70.03 \\
\pm 42.41\end{array}$ & $\begin{array}{l}7.34 \pm \\
4.97\end{array}$ & $\begin{array}{l}92.00 \\
\pm 53.49\end{array}$ & $\begin{array}{l}62.28 \pm \\
37.10\end{array}$ & $9.52 \pm 6.92$ \\
\hline
\end{tabular}

with water droplet. However, no correlation was found in this study about variation of aerosol concentration with the wind speed (Fig. 2). In the year 2016, the lowest concentration of $\mathrm{PM}_{2.5}$ is $25.8,31.7$, and $18.3 \mu \mathrm{g} / \mathrm{m}^{3}$ and highest concentration is 152.0, 181.0, $178.7 \mu \mathrm{g} / \mathrm{m}^{3}$ at Nawabganj, Manikganj, and Dhaka city,
Inspite of the presence of power plant at suburban sites (Manikganj and Nawab-ganj) the annual average concentrations of fine and coarse particles $\left(\mathrm{PM}_{2.5}\right.$ and $\left.\mathrm{PM}_{10}\right)$ at urban site (Dhaka city) are high. The high concentration of PM at Dhaka is due to the emissions from huge number of increased motor vehicles running by gasoline 


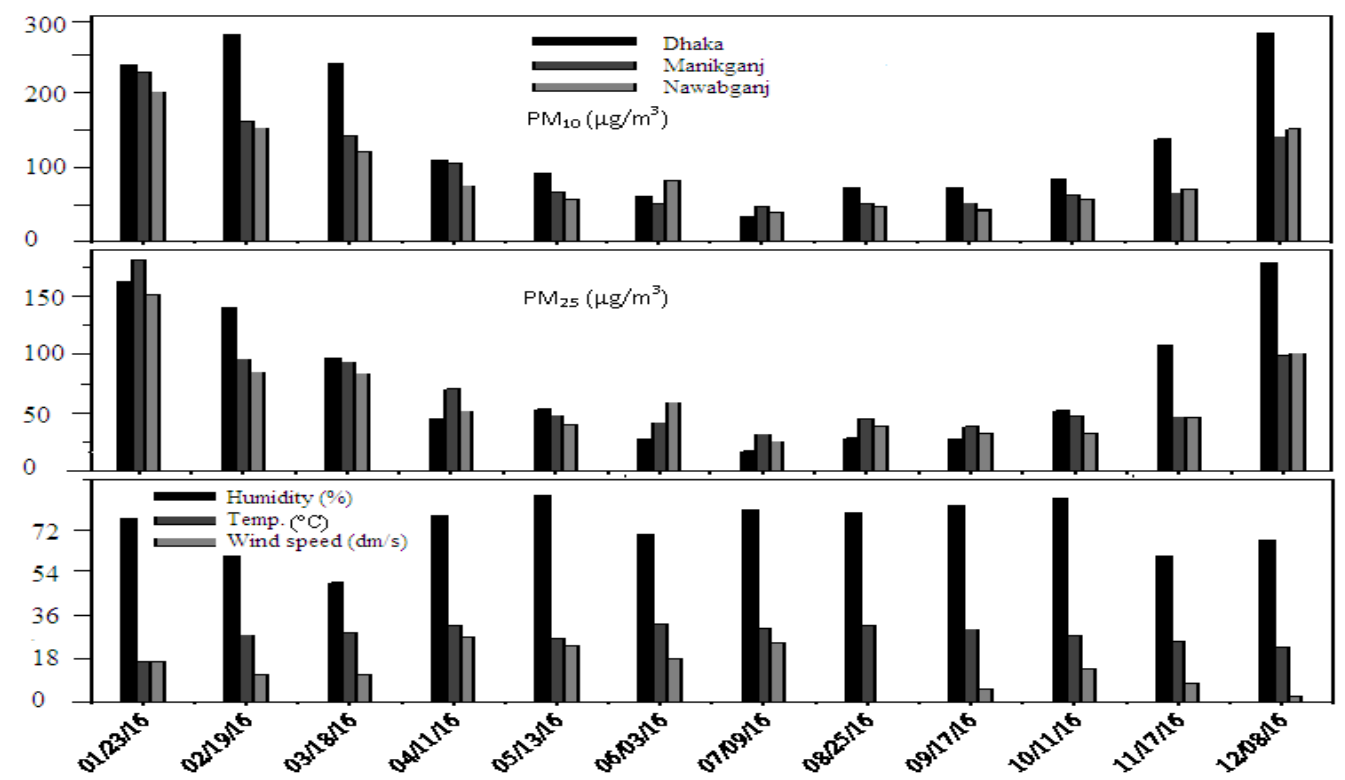

Fig. 2. Monthly basis variation of mass concentration of $\mathrm{PM}_{10}$ and $\mathrm{PM}_{2.5}$ during the year 2016 at three sites: Dhaka city, Manikganj, and Nawabganj.

and diesel engines, domestic fuel burning, traffic-induced street dust, and from play grounds. Other main source of PM is resuspension from the entire dusty unpaved street during road digging of Water Supply and Sewerage Authority (WASA) and Dhaka Electric Supply Company Ltd. (DESCO) and other service providing authority throughout the winter season. On the other hand, both the power plants at Manikganj and Nawabganj sites use emission control system including Flue Gas Desulfurization (FGD).

Comparison of PM mass concentration with Standard

Among the three sites, air of Dhaka city is the most polluted and Nawabganj is least polluted based on average concentrations of $\mathrm{PM}_{10}$ and $\mathrm{PM}_{2.5}$ of city, Dhaka and its neighbors Manikganj, and Nawabganj (Fig. 3 and Table 1).

The average concentrations of $\mathrm{PM}_{10}$ at Dhaka city are $143.16( \pm 92.85) \mu \mathrm{g} / \mathrm{m}^{3}$ which is 1.56 , and 1.45 times higher than that of Manikganj and Nawabganj, respectively. Alternatively, the average yearly value of $\mathrm{PM}_{2.5}$ concentrations of Dhaka city is $78.52( \pm 57.05) \mu \mathrm{g} / \mathrm{m}^{3}$ which is 1.26 and 1.12 times higher than Manikganj and Nawabganj, respectively. For the less hazardous coarse particulate matter $\mathrm{PM}_{10}$, in all three sites have higher than the daily standard values of EPA, BNAAQS and WHO recommendation. For the most hazardous fine particulate matter $\mathrm{PM}_{2.5}$, the concentrations in all the places Dhaka city and Manikganj are also higher than the standard value of WHO, EPA, and BNAAQS.

\section{Black Carbon (BC) Concentration}

The mass concentration $\mathrm{BC}$ at Nawabganj was found higher than that of Manikganj ( Fig. 4 and Table 1). In both sites the BC mass concentration was higher in winter season (December-February). However, in rainy season (June-November) it significantly reduced. Therefore, meteorological conditions have a greater impact on $\mathrm{BC}$ mass concentration. It increases in winter season due to lower humidity and temperature at that time. 


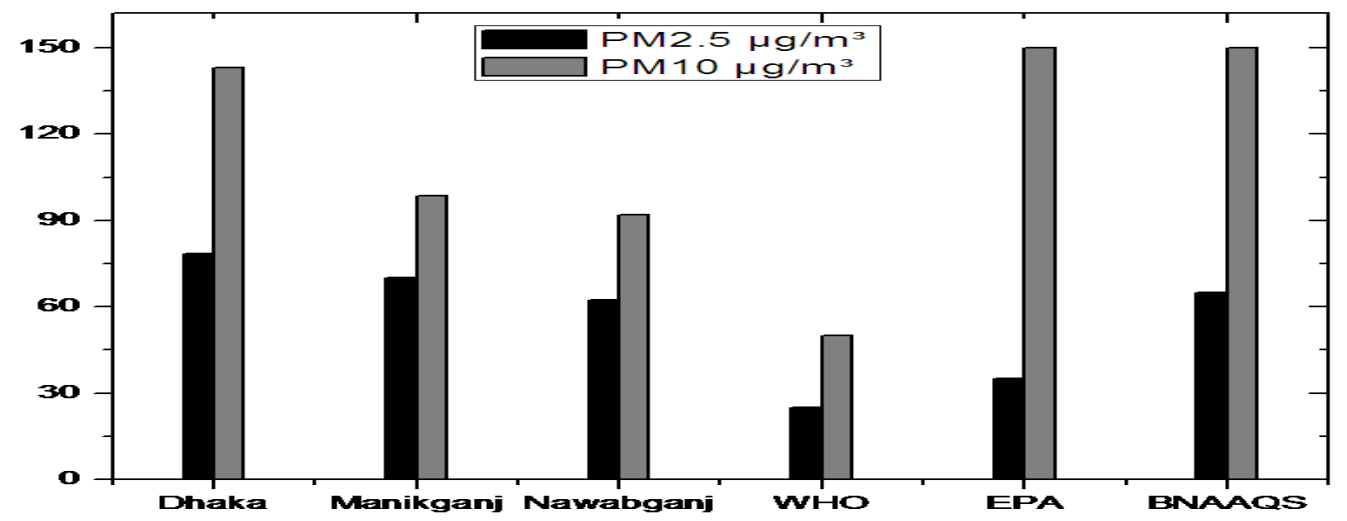

Fig. 3. Comparison of the PM mass concentration at three different sites with standard value of WHO, EPA, and BNAAQS.

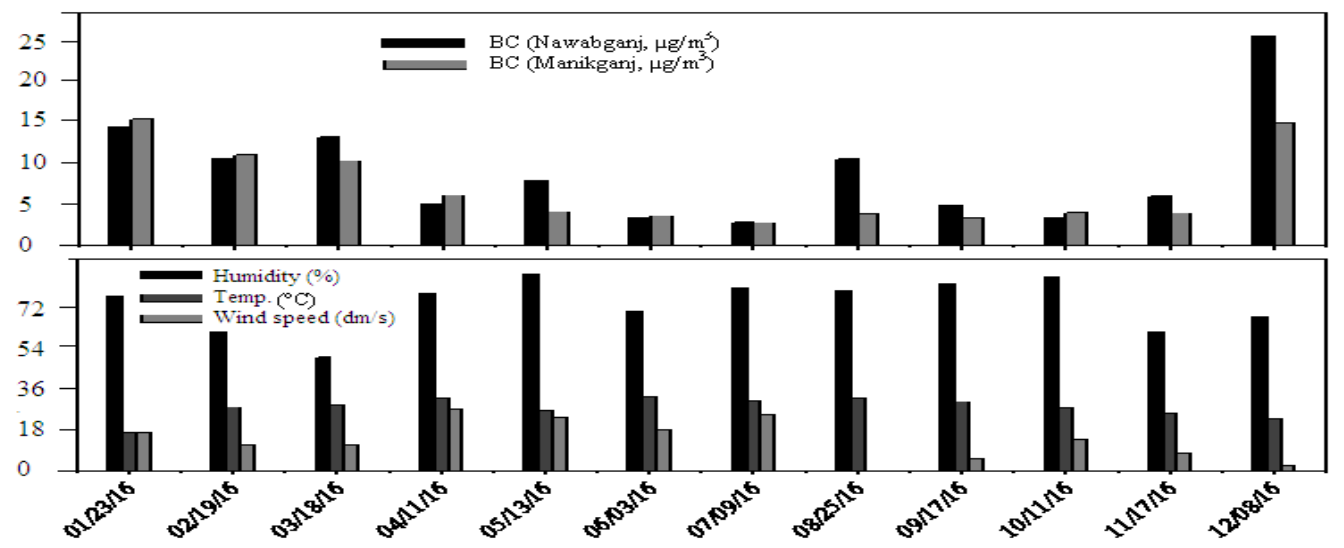

Fig. 4. Comparison of BC mass concentration at Manikganj and Nawabganj with meteorological conditions during the year 2016.

\section{Ratios of $P M_{2.5} / P M_{10} \& B C / P M_{2.5}$}

The annual average $\mathrm{PM}_{2.5} / \mathrm{PM}_{10}$ ratio at Dhaka city is 0.53 however, at Nawabganj and Manikganj (suburban sites) this ratio is increase to 0.68 and 0.72 , respectively. $\mathrm{Xu}$ et al. (2017) reported that in Asia, generally the ratio is less than 0.5 and follows a spatial gradient where the ratio increases from urban to suburban area. In the present studies, the higher value of $\mathrm{PM}_{2.5} / \mathrm{PM}_{10}$ ratio at suburban sites compared to urban area is also observed. This might be due to establishment of HFO based power plants with compression ignition engines at those sites.
On the other hand, the life time of $\mathrm{PM}_{2.5}$ is higher therefore they can be transported from other places; consequential higher ratios of $\mathrm{PM}_{2.5} / \mathrm{PM}_{10}$ [Parkhurst et al. 1999; Zhou et al. 2016] in Dhaka during dry season. The seasonal variation of $\mathrm{PM}_{2.5} / \mathrm{PM}_{10}$ ratio follows differently at urban and suburban area. At suburban sites the $\mathrm{PM}_{2.5} / \mathrm{PM}_{10}$ ratio is higher in rainy season than dry season as these are locally produced; while at urban site this is higher in winter season due to transport from outside the city than rainy season. On the other hand, black carbon in $\mathrm{PM}_{2.5}$ is $10 \%$ and $15 \%$, at Manikganj, and Nawabganj, respectively as shown in Fig. 5. However, at 
Manikganj the $\mathrm{BC} / \mathrm{PM}_{2.5}$ ratio doesn't show any seasonal variation as both are locally produced at the power plants. the emissions from brick kilns especially to the north of the city which are blown into the city due to prevailing wind from the north and north-

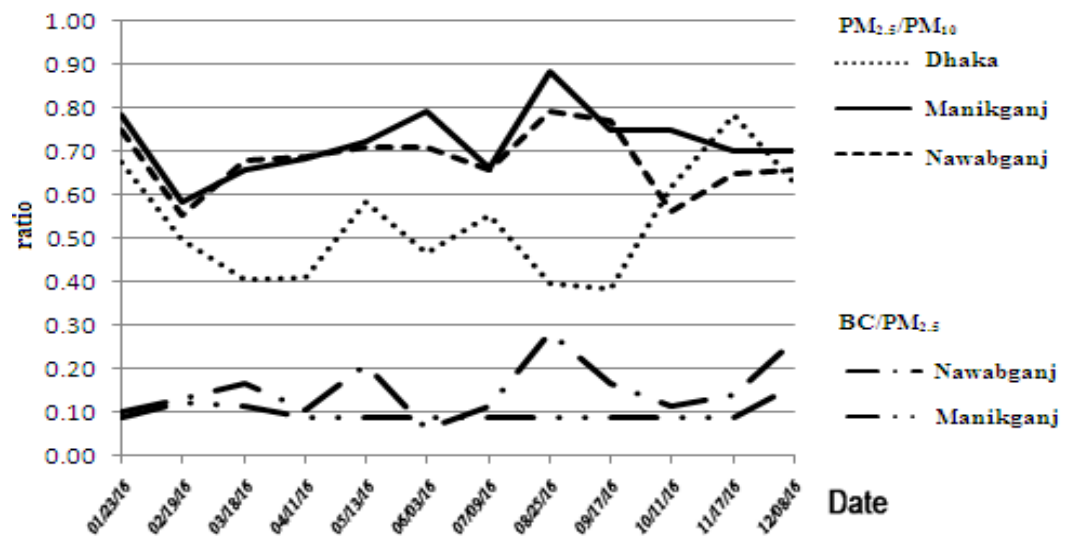

Fig. 5. The seasonal variation of $\mathrm{PM}_{2.5} / \mathrm{PM}_{10}$ and $\mathrm{BC} / \mathrm{PM}_{2.5}$ during the year 2016 at three sites: Dhaka city, Manikganj, and Nawabganj

\section{CONCLUSIONS}

The annual average concentrations of $\mathrm{PM}_{10}$ and $\mathrm{PM}_{2.5}$ were $143.16 \mu \mathrm{g} / \mathrm{m}^{3}$ and $78.52 \mu \mathrm{g} / \mathrm{m}^{3}$, respectively in Dhaka city during January to December 2016. At Dhaka city, the average $\mathrm{PM}_{10}$ concentration is 1.45 and 1.56 times higher and the average $\mathrm{PM}_{2.5}$ concentrations. These values are 1.12 and 1.26 times higher than Manikganj and Nawabganj respectively. Likewise, the mass concentration of $\mathrm{BC}$ is slightly higher at Nawabganj than that of Manikganj. The mass concentration of both PM and $\mathrm{BC}$ is higher in winter season and lower in rainy season. The decrease of mass concentration of PM and $\mathrm{BC}$ in rainy season is due to reduced suspension time causing high humidity and rainfall at that time.

During the year 2016 air at all the monitoring stations Dhaka city, Nawabganj and Manikganj had higher amount of fine hazardous PM $\left(\mathrm{PM}_{2.5}\right)$ compared with the standard value of WHO, EPA, and BNAAQS. Moreover, the $\mathrm{PM}_{2.5} / \mathrm{PM}_{10}$ ratio is higher at suburban areas compared to urban area. Therefore, the presence of HFO (Heavy Fuel Oil) based power plant has modest impact on air quality.

The reason for the high concentrations of fine particles $\left(\mathrm{PM}_{2.5}\right)$ in Dhaka city in winter is due to west. Other main source of $\mathrm{PM}_{10}$ is resuspension from the dusty unpaved streets.

\section{REFERENCES}

Azad, A. K., T. Kitada, 1998. Character-istics of the air pollution in the city of Dhaka, Bangladesh in winter. Atmos-pheric Environment 32: 1991-2005.

Bangladesh Road transport Authority http:// www.brta.gov.bd/.

Bangladesh Bureau of Statistics, http:// www.bbs.gov.bd/.

Bangladesh Bureau of Statistics, District statistics, 2011, Dhaka, published 2013.

Begum B. A., S. K. Biswas \& P. K. Hopke, 2006, Impact of Banning of Two-Stroke Engines on Airborne Particulate Matter Concentrations in Dhaka, Bangladesh, Journal of the Air \& Waste Management Association, 56: 85- 89.

Begum, B. A., S. Akhter, L. Sarker, and S. K. Biswas, 2006, Gravemetric analysis of air filters and quality assurance in weighing, Nucl. Sci. and appl., 15: 36-41. 
Biswas S. K., S. A. Tarafdar, A. Islam, M. Khaliquzzaman, H. Tervahattu, and K. Kupiainen, 2003, Impact of unleaded gasoline introduction on the concentration of lead in the air of Dhaka, Bangladesh. $J$. Air and Waste Management Association 53: 1355-1362.

Banglapedia, National Encyclopedia of Bangladesh. http:// en.banglapedia.org/ index. php?title=Main_Page.

Clean air and Sustainable Environment, Ministry of Environment, 2015, http:// case.doe. gov. bd/ index. php? option= com_content\& view $=$ article $\& i d=9 \&$ Itemid $=31$.

Kojima, M., C. Brandon, J. Shah, 2000. Improving Urban Air Quality in South Asia by Reducing Emissions from Two-Stroke Engine Vehicles; South Asia Environment Unit of the World Bank Report: Washington, DC.

Lin, J., L. C. Lee, 2004. Characterization of the concentration and distribution of urban submicron $\left(\mathrm{PM}_{1}\right)$ aerosol particles. Atmospheric Environment 38: 469-475.

Namdeo, A., M. C. Bell, 2005. Characteristics and health implications of fine and coarse particulates at road side, urban background and rural sites in UK. Environment International 31: 565-573.
Parkhurst, W. J., R. L. Tanner, F. P. Weatherford, R. J. Valente, and J. F. Meagher, (1999). Historic $\mathrm{PM}_{2.5} / \mathrm{PM}_{10}$ concentrations in the Southeastern United States-potential implications of the revised particulate matter standard. J. Air Waste Manage. Assoc. 49: 1060-1067.

Salam, A., M. B. Ullah, M. D. Islam, M. A. Salam, S. M. Ullah, 2011. Carbonaceous species in total suspended particulate matters at different urban and suburban locations in the Greater Dhaka region, Bangladesh. Air Quality, Atmosphere and Health. doi:10.1007/s11869-011-0166-z.

Xu Gang, L. Jiao, B. Zhang, S. Zhao1, M. Yuan, Y. Gu, J. Liu1, X. Tang. 2017. Spatial and Temporal Variability of the PM2.5/PM10 Ratio in Wuhan, Central China, Aerosol and Air Quality Research, 17: 741-751.

Zhou, X., Z. Cao, Y. Ma, L. Wang, R. Wu, W. Wang. 2016. Concentrations, correlations and chemical species of $\mathrm{PM}_{2.5} / \mathrm{PM}_{10}$ based on published data in china: Potential implications for the revised particulate standard. Chemosphere 144: 518-526.

(Received revised manuscript on 30 May 2019) 